\title{
Intravenous Iron Is Effective and Safe in Correcting Anemia in Erythropoietin-Treated Hemodialysis Patients
}

\author{
Mahmoud H Ayesh (Haj Yousef), Ahnaf M Bataineh, Mohamed Rababeih, Sulieman M Momani, Khaldoon Alawneh \\ Department of Internal Medicine, King Abdullah University Hospital, Faculty of Medicine, Jordan University of Science and \\ Technology, P.O. Box 3030 Irbid 22110, Jordan
}

\author{
Citation: Ayesh MH, Bataineh AM, Rababeih \\ M, Momani SM, Alawneh K. Intravenous Iron Is \\ Effective and Safe in Correcting Anemia in \\ Erythropoietin-Treated Hemodialysis Patients. \\ Maced J Med Sci. 2013 Mar 15:6(1):41-43. \\ http://dx.doi.org/10.3889/MJMS.1857-5773.2013.0254. \\ Key words: Intravenous iron; hemodialysis; \\ erythropoietin; anemia; ferritin. \\ Correspondence: Mahmoud $\mathrm{H}$ Ayesh ( $\mathrm{Haj}$ \\ Yousef). Jordan University of Science and \\ Touser. \\ Technology, P.O. Box 3030, Irbid 22110 , \\ ayeshmahmoud@hotmail.com \\ Received: 09-Jul-2012; Revised: 16-Aug- \\ 2012; Accepted: 19-Aug-2012; Online first: \\ 04-Feb-2013 \\ Copyright: (c) 2013 Ayesh MH. This is an \\ open-access article distributed under the terms \\ of the Creative Commons Attribution License, \\ which permits unrestricted use, distribution, \\ and reproduction in any medium, provided the \\ original author and source are credited. \\ Competing Interests: The author have \\ declared that no competing interests exist.
}

\begin{abstract}
Objectives: To study the effect of intravenous iron in the management of anemia in erythropoietin (EPO) treated hemodialysis patients with poor response to treatment with oral iron.

Methods: Thirty-six patients (27 men and 9 women) with serum hemoglobin of less than $10 \mathrm{~g} / \mathrm{dl}$ and a serum ferritin level of less than $500 \mathrm{mcg} / /$ were included in the study. Each patient received $100 \mathrm{mg}$ of intravenous iron at end of dialysis for 10 consecutive dialysis treatments, and once weekly of regular intravenous iron supplementation for another 13 weeks included in the study. All patients were receiving oral iron supplements (ferrous sulphate $325 \mathrm{mg}$ twice daily), and were all also receiving EPO, a total dose of 8000 units per week, given subcutaneous as 4000 unit twice weekly throughout the study. The primary end point of this study was hemoglobin level at 4 months of starting intravenous iron supplementation.

Results: The mean hemoglobin increased from $8.88 \mathrm{~g} / \mathrm{dl}$ to $11.18 \mathrm{~g} / \mathrm{dl}$ over the period of the study (4 months) $(p<0.0001)$. The mean serum ferritin increased from $179 \mathrm{mcg} / \mathrm{l}$ to $444 \mathrm{mcg} / \mathrm{l}$ over the same period $(\mathrm{P}<0.0001)$.
\end{abstract}

Conclusion: Intravenous iron supplementation is very effective in correcting a poor response to EPO in hemodialysis patients on oral iron supplements.

\section{Introduction}

The relationship of adequate iron stores and achieving maximum benefit from erythropoietin (EPO) in the treatment of anemia of advanced renal failure is well recognized [1-3]. EPO causes mobilization of iron from iron stores to be used up in the manufacture of new red blood cells. Many patients who have borderline iron stores at the start of EPO therapy may develop absolute iron deficiency [4], or even patients with excessive iron stores may develop functional iron deficiency when the iron from these stores is not released fast enough to satisfy the needs of the bone marrow for erythropoiesis [5]. Therefore, unless supplemental iron therapy is given, decreased iron stores or decreased availability of iron (functional iron deficiency) is a common reason for resistance to the effect of EPO. Oral iron is usually not well tolerated because of adverse gastrointestinal effects; this usually leads to poor compliance by most of the patients to overcome these problems in patients in whom oral iron is poorly tolerated Intravenous iron preparations were developed. Therefore this study is designed to examine the benefits of regular intravenous iron administration in hemodialysis patients treated with EPO and oral iron with poor response as indicated by low hemoglobin level.

\section{Method}

This retrospective observational study was approved by the Institutional Review Board (IRB) of King Abdullah University Hospital (KAUH). This study was performed in the outpatient dialysis unit at King $\mathrm{KAUH}$, an 800-bed tertiary care center located in north of Jordan over a period of one year. All patients included in this study were diagnosed and treated at KAUH. Thirty six patients (9 men and 27 women; mean age 47 year) receiving regular hemodialysis for 
end-stage renal failure though AV fistulae were enrolled in this study. All patients received the same type of EPO (epoetin alpha).

The selection criteria for enrolment in the study were as listed below: (1) patients on hemodialysis on oral iron tablets; (2) patients on hemodialysis on same type and EPO dose which is 4000 unit twice weekly subcutaneous; (3) patients with no evidence of bleeding; (4) patients who did not receive any blood transfusion 6 months prior to the intravenous iron and during the time of intravenous iron treatment.

However, the Exclusion criteria were as follows: (1) patients on hemodialysis who have anemia not related to iron deficiency; (2) patients who were not taking oral iron supplement; (3) patients with change in the dose of EPO throughout the study period; (4) patient with change in the dialysis regimen throughout the study period.

All hemodialysis patients with the serum ferritin level less than $500 \mathrm{mcg} / \mathrm{L}$ [6], and hemoglobin level less than $10 \mathrm{~g} / \mathrm{dl}$ were included in the study, six to nine months prior to the start of intravenous iron supplementation all patients were receiving oral iron supplements (ferrous sulphate $325 \mathrm{mg}$ bid), and same EPO (epoetin alfa), a total dose of 8000 unit per week, given subcutaneous as 4000 unit twice weekly throughout the study were selected for the study. The intravenous iron supplementation regimen involved giving $100 \mathrm{mg}$ of iron sucrose as infusion over 15 minutes into the venous limb of the patients' vascular access at the end of dialysis treatment. Each patient received intravenous iron at end of dialysis for 10 consecutive dialysis treatments and once weekly of regular intravenous iron supplementation thereafter was selected for the study.

All patients had been on dialysis for less than eighteen months, they were all dialyzed through an arteriovenous fistula. The mean starting hemoglobin level was $8.88 \mathrm{~g} / \mathrm{dl}$. The mean serum ferritin level for the group was $179 \mathrm{mcg} / \mathrm{l}$. The primary end point of the study was hemoglobin concentration at 4 months of starting IV iron supplementation. Hemoglobin levels were measured at baseline and every 2 months, thereafter. Ferritin was measured again at the end of the study.

\section{Statistical analysis}

The pre-study and post-treatment samples were obtained after 4 months of intravenous iron administration. The pre-study and post-treatment values have been processed with descriptive methods (mean and standard deviation for the parameters with normal distribution, median and interquartile range for non-parametric data). A $P$-value of less than 0.05 was considered statistically significant

\section{Results}

\section{Hemoglobin}

Before starting the intravenous iron protocol, the mean (SD) hemoglobin level was $8.88(0.91) \mathrm{g} / \mathrm{dl}$. following introduction of the IV iron protocol, the mean (SD) hemoglobin level for all hemodialysis patients showed gradual increase over the subsequent 4 months reaching 11.18 (1.25) $\mathrm{g} / \mathrm{dl}(\mathrm{p}<0.0001)$.

\section{Ferritin}

Intravenous iron supplementation caused a significant increase in serum ferritin levels from a mean (SD) of $179 \mathrm{mcg} / \mathrm{l}$ at the beginning of the study to $444(\mathrm{mcg} / \mathrm{l}$ at the end of the study.

\section{EPO Dose}

Patients were receiving same EPO of 8000 U/week; there was no attempt to decrease this dose over the period of the study. All patients continued to receive 4000 units of EPO twice weekly, subcutaneous, throughout the study.

\section{Reactions to intravenous iron}

In total around 850 injections of intravenous iron were given during the period of the study. Not a single adverse reaction (itching, dyspnea, wheezing, chest pain, hypotension, fever or arthralgia) was reported. However 3 patients complained of metallic taste in their mouths associated with the injection.

\section{Discussion}

This study was conducted in a retrospective manner to assess the effect of aggressive intravenous iron supplementation on the treatment of anemia in hemodialysis patients. The results were an astonishing increase in hemoglobin levels. This effect can be attributed solely to the introduction of intravenous iron, as all patients studied were on a stable dose both of oral iron and EPO that didn't change throughout the study period. Moreover, the hemodialysis patients included in this study were stable and no changes in dialysis regimens were introduced or other treatments were started.

In most patients, even those with strict attention to compliance, anemia fails to correct despite oral iron therapy this is related to the fact that the dialysis patient is in a state of continuous iron loss, thereby indicating the need for parenteral iron [7]. Oral iron supplementation usually provides safe and cheap way of restoring iron balance. However iron 
absorption is affected by multiple factors like food as it binds and impair its absorption, patients also develop upper gastrointestinal discomfort related to oral iron, which also affect their compliance [8].

This study is consistent with other studies that showed that in iron deficient hemodialysis patients randomized to oral iron or intravenous iron, only the group treated with intravenous iron had a significant increase in hemoglobin levels [9-12]. Intravenous iron preparations have very different molecular weights and side effect profiles [13], small proportions of patients given intravenous iron dextran develop a lifethreatening anaphylactic reaction, which is due to an immune-mediated reaction in patients who have dextran antibodies [14]. This study also shows an excellent safety record of iron sucrose. The limitation of this study is the small number of patients included in this study. However, a larger number of patients is required.

In conclusion oral iron is of limited benefit in correcting anemia in patients on hemodialysis with poor response to EPO. However, intravenous iron supplementation is very effective and safe in correcting anemia in those patients. Regular and frequent intravenous iron is needed in the majority of hemodialysis patients on EPO for improving the hemoglobin level and reduces the dose of EPO.

\section{References}

1. Yong $\mathrm{K}$, Kairaitis $\mathrm{L}$. Effects of proactive iron and erythropoiesis-stimulating agent protocol implementation on achieving clinical guideline targets for anaemia in a satellite haemodialysis patient cohort. Nephrology (Carlton). 2010;15(3):288-93.

2. Richardson D. Clinical factors influencing sensitivity and response to epoetin. Nephrol Dial Transplant. 2002; 17(Suppl 1):53-9.

3. Agarwal AK. Practical approach to the diagnosis and treatment of anemia associated with CKD in Elderly. J Am Med Dir Assoc. 2006;7(9 Suppl):S7-S12; quiz S17-21.
4. Van Wyck DB. Iron management during recombinant human erythropoietin therapy. Am J Kidney Dis. 1989;14(2 Supp 1):913.

5. Fishbane S. Iron supplementation in renal anemia. Seminar Nephrol. 2006;26(4):319-24.

6. National Collaborating Centre for Chronic Conditions. Anaemia management in chronic kidney disease (CG39). London: National Institute for Health and Clinical Excellence, September 2006.

7. Kalantar-Zadeh K, Streja E, Miller JE, Nissenson AR. Intravenous iron versus erythropoiesis-stimulating agents: friends or foes in treating chronic kidney disease anemia? Adv Chronic Kidney Dis. 2009;16(2):143-51.; 14:271.

8. Agarwal R, Warnock D. Issues related to iron replacement in chronic kidney disease. Semin Nephrol. 2002; 22 (6):479-87.

9. Albaramki J, Hodson EM, Craig JC, Webster AC. Parenteral versus oral iron therapy for adults and children with chronic kidney disease. Cochrane Database Syst Rev. 2012;1(CD007857): 51:24.

10. Qunibi WY, Martinez C, Smith M, Benjamin J, Mangione A, Roger SD. A randomized controlled trial comparing intravenous ferric carboxymaltose with oral iron for treatment of iron deficiency anaemia of non-dialysis-dependent chronic kidney disease patients. Nephrol Dial Transplant. 2011;26(5):1599-607.

11. Rozen-Zvi B, Gafter-Gvili A, Paul M, Leibovici L, Shpilberg O, Gafter U. Intravenous versus oral iron supplementation for the treatment of anemia in CKD: systematic review and metaanalysis. Am Kidney Dis. 2008;52(5):897-906.

12. Tagboto S, Cropper L, Mostafa S, Turner J, Bailey G, PughClarke K. Intravenous iron in chronic kidney disease: haemoglobin change shortly after treatment of patients neither on dialysis nor on erythropoietin. J Ren Care. 2008; 34(3):112-

13. Jahn MR, Andreasen $H B$, Fütterer $S$, Nawroth $T$, Schünemann $V$, Kolb U, Hofmeister W, Muñoz M, Bock $K$, Meldal $M$, Langguth PA comparative study of the physicochemical properties of iron isomaltoside 1000 (Monofer), a new intravenous iron preparation and its clinical implications. Eur J Pharm Biopharm. 2011;78(3):480-91.

14. Macdougall IC. Evolution of IV iron compounds over the last century. J Ren Care. 2009;35 Suppl 2:8-13. 